\title{
A VIOLAÇÃO DOS DIREITOS DA PERSONALIDADE DO IDOSO NO ÂMBITO FAMILIAR
}

\author{
Maria de Lourdes Araújo Cavalcanti Mundim*
}

RESUMO: Este artigo resulta de pesquisa abrangendo a violação dos direitos da personalidade da população idosa que vem crescendo no mundo todo, nas últimas décadas, conforme apontam dados estatísticos oficiais analisados. Busca refletir acerca das causas e possíveis caminhos alternativos a serem construídos na consolidação dos valores constitucionais dirigidos aos idosos e na efetiva implementação da doutrina da proteção integral que imputa tal responsabilidade solidariamente à família, à sociedade e ao Estado.

Palavras-chave: Idoso. Violação. Direitos da personalidade. Ambiente familiar. Personalidade do idoso.

\section{THE VIOLATION OF THE RIGHTS OF THE PERSONALITY OF THE ELDERLY IN THE FAMILY FRAMEWORK}

ABSTRACT: This article is the result of research covering one of the rights of the personality of the elderly population that has been growing worldwide in recent decades, according to official statistical data analyzed. It seeks to reflect on the causes and possible alternative paths to be built in the consolidation of the constitutional values directed to the elderly and in the effective implementation of the doctrine of integral protection that impute such responsibility jointly to the family, society and the State.

Keywords: Elderly. Violation. Personality Rights. Family Atmosphere. Personality of the elderly

\footnotetext{
* Discente do Curso de Pós-Graduação em Ciências Jurídicas, nível mestrado, do Centro Universitário de Maringá - UNICESUMAR e Juíza de Direito do Tribunal de Justiça do Estado do Paraná, titular da vara cível da Comarca de Colorado. Email: equipelourdes@hotmail.com Endereço postal: Tribunal de Justiça do Paraná, Comarca de Colorado. Rua Rafaine Pedro, Centro, Colorado - PR.
} 


\section{INTRODUÇÃO}

O cuidado e a proteção ao idoso no âmbito natural da família, que já foi por muitas vezes temática do cancioneiro popular em melodiosos versos e prosas, cada vez mais vem ganhando ares de positividade insertos em textos legais de especial grandeza, como o que podemos observar da leitura atenta do contido no art. 230 da Constituição Federal de 1988.

Isto reflete uma realidade ainda não incorporada pela sociedade: conquistamos longevidade! Dados da Secretaria Nacional de Direitos Humanos da Presidência da República - Coordenação Geral de Direitos do Idoso (BRASIL, 2018) indicam que, segundo projeções das Nações Unidas (Fundo de Populações), uma em cada nove pessoas no mundo tem 60 (sessenta) anos ou mais; e estima-se um crescimento ao patamar de um em cada cinco por volta de 2050, quando, pela primeira vez, haverá mais idosos que crianças menores de 15 anos. Em 2010 a população idosa no Brasil correspondia a apenas 10\% do total da população (19,6 milhões) e, estimativa do Instituto Brasileiro de Geografia e Estatística - IBGE para 2050 é de uma elevação para 29,3\%. A reviravolta efetiva deverá ocorrer por volta de 2030, quando o número de idosos deve chegar a $18 \%$ da população (41,5 milhões). No mesmo período, o número de crianças deverá estar em torno de 17,6\% da população (LEAL, 2016). Atualmente apenas o Japão conta com mais de 30\% da população composta de idosos, e, para 2050 projetase esta mesma realidade para 64 países. (UNFPA, 2018)

Partindo desta perceptiva e das implicações pessoais e sociais, este artigo objetiva discutir os estudos e elementos disponíveis nos bancos de dados de organismos e instituições nacionais e internacionais que condensam subsídios relevantes acerca da violação dos direitos deste segmento etário vulnerável, na circunscrição da família enquanto primeira comunidade reunida pelo laço do afeto. Como método de trabalho e buscando alcançar um resultado fiel, foram realizadas análises bibliográfica, legislativa, doutrinária e jurisprudencial, visando a exposição do quadro atual e da construção de estratégias possíveis para o enfrentamento deste dilema global.

A longevidade refletida nos números é atribuída a fatores como avanços na área da medicina, maior eficácia das campanhas de vacinação em massa, atenção ao pré-natal, incentivo ao aleitamento materno e programas de nutrição infantil, melhoras das condições sanitárias, cuidados com saúde, ensino e bem-estar econômicos. Imputa-se uma considerável elevação na 
expectativa de vida dos brasileiros, que já de 1940 a 2016 aumentou em 30,3 anos, passando de 45,8 para 75,8 anos. (OLIVEIRA, 2017)

Se por um lado esta constatação representa o triunfo do desenvolvimento humano, significando uma das maiores conquistas culturais de um povo em seu processo de eclosão, por outro importa na necessidade de construção de novos hábitos e políticas públicas (BUCCI, 2013) destinadas ao atendimento desta população fragilizada pela diminuição da higidez dos órgãos, funções e sentidos, nas áreas da previdência, assistência social, saúde, trabalho, cultura, dentre outras.

\section{O IDOSO NO ÂMBITO DA FAMÍLIA, DA SOCIEDADE E DO ESTADO}

Por consequência destas transformações demográficas e sociais, como é próprio no direito, o cenário jurídico também se move em vista de novas demandas. Há muito que a temática do idoso frequenta a agenda das instituições, organismos e instâncias internacionais, em amplos painéis de debates e discussões, construção de acordos e termos de compromissos.

No horizonte internacional, a Assembleia Geral da Organização das Nações Unidas convocou para Viena a primeira Assembleia Mundial sobre o Envelhecimento, no ano de 1982. Em decorrência dos debates então travados, foi produzido um Plano de Ação Internacional sobre o Envelhecimento, refletido em 62 recomendações para ações de pesquisa, coleta e análise de dados, treinamento e educação, nas áreas de saúde e nutrição, proteção de consumidores idosos, habitação e meio ambiente, família, bem-estar social, segurança e renda, emprego e segurança. Foi o primeiro documento a se dedicar ao tema no cenário mundial.

A Assembleia Geral adotou o Princípio das Nações Unidas em Favor das Pessoas Idosas, em 1991, elencando como direitos deste segmento vitimizado, a independência, a participação, o cuidado, a autorrealização e a dignidade. Neste último tema, assentou-se com clareza o direito do idoso de "poder viver com dignidade e segurança, sem ser objeto de exploração e maus-tratos físicos e/ou mentais.” Em 1992, seguindo no Plano de Ação anteriormente estabelecido, a Conferência Internacional sobre o Envelhecimento promoveu a Proclamação do Envelhecimento, conclamando a comunidade internacional a alavancar a implementação do Plano de Ação Internacional sobre o Envelhecimento, além de eleger 1999 como o Ano Internacional das Pessoas Idosas.

A segunda assembleia com a mesma temática ocorreu em Madri, no ano de 2002. Nesta senda, as discussões resultaram na adoção, pelos países participantes, de dois documentos 
relevantes: uma Declaração Política e o Plano de Ação Internacional de Madri sobre o Envelhecimento. Ambos continham compromissos dos governos para elaborar e implementar medidas de enfrentamento dos desafios postos pelo envelhecimento, além de mais de 100 recomendações para a implementação de ações efetivas abrangendo: as pessoas idosas e desenvolvimento; avanços na saúde e bem-estar na velhice; garantia de ambientes facilitadores e de apoio (UN, 2002). Nos dois eventos internacionais foi destacada, como prioridade, a aplicação da Declaração Universal dos Direitos Humanos e a necessidade de inclusão do idoso na vida social, cultural, econômica e política das sociedades.

No panorama interno, a Constituição Federal de 1988, enquanto pacto social fundante do Estado e garantidor dos direitos fundamentais básicos, expressamente previu no art. 230 que a família, a sociedade e o Estado têm o dever de amparar as pessoas idosas, assegurando sua participação na comunidade, defendendo sua dignidade e bem-estar e garantindo-lhes o direito à vida, ostentando uma clara opção pela manutenção do idoso em seu lar, ao estatuir que os programas de amparo aos idosos serão executados, preferencialmente, em seus lares. Até então, não havia uma legislação específica para definir conceitualmente o idoso, o que ocorreu em 2003, quando a Lei 10.741 - intitulado Estatuto do Idoso - deliberou, com base exclusivamente no critério etário, que idoso é a pessoa com idade igual ou superior a 60 (sessenta) anos.

É uma legislação tida como moderna e vanguardista, consubstanciando-se num verdadeiro microssistema jurídico de proteção ao idoso, seguindo a mesma linha trilhada anteriormente pelas Leis 8.069/90 e 8.078/90, Estatuto da Criança e do Adolescente e o Código de Defesa do Consumidor, respectivamente. Esta legislação incorporou e ratificou a chamada doutrina da "proteção integral" (art. $2^{\circ}$ ), implicando no reconhecimento de que o idoso é titular de direitos fundamentais e sociais que devem ser assegurados por todos, seja a família, a sociedade ou o Estado.

A Lei n. ${ }^{\circ} 8.884 / 94$ dispôs sobre a Política Nacional do Idoso, com o objetivo de assegurar os direitos sociais ao idoso, criando condições para promover sua autonomia, participação efetiva e integração na sociedade. Dispôs de forma bem didática, nove pontos de ação para o atingimento de sua finalidade: a viabilização de formas alternativas de participação, ocupação e convívio do idoso, que proporcionem sua integração às demais gerações; a participação do idoso, através de suas organizações representativas, na formulação, implementação e avaliação das políticas, planos, programas e projetos a serem desenvolvidos; a priorização do atendimento ao idoso por intermédio de suas próprias famílias, em detrimento do atendimento asilar, à exceção dos idosos que não possuam condições que garantam sua própria sobrevivência; a descentralização político-administrativa; a capacitação e reciclagem dos recursos humanos nas áreas de geriatria e gerontologia e na prestação de serviços; a implementação de sistema de informações que permita a divulgação da política, dos serviços oferecidos, dos planos, programas e projetos em cada nível de governo; o estabelecimento de mecanismos que favoreçam a divulgação de informações de caráter educativo sobre os aspectos biopsicossociais do envelhecimento; a priorização do atendimento ao idoso em órgãos públicos e privados prestadores de serviços, quando desabrigados e sem família e; apoio a estudos e pesquisas sobre as questões relativas ao envelhecimento (BRASIL, 1994). 
No plano infralegal interno, o Decreto $n^{\circ} 4.227 / 2002$ criou o Conselho Nacional dos Direitos do Idoso, vinculado ao Ministério da Justiça, competente para supervisionar e avaliar a Política Nacional do idoso. Sob a perspectiva do Poder Executivo, o Brasil possui um Plano de Ação para o Enfrentamento da Violência contra a Pessoa Idosa, afeto à Secretaria Nacional de Direitos Humanos da Presidência da República, com o objetivo de promover ações que levem ao cumprimento do Estatuto do Idoso (Lei $\mathrm{n}^{\circ} 10.741$, de $1^{\circ}$ de outubro de 2003), que tratem do enfrentamento da exclusão social e de todas as formas de violência contra esse segmento etário (BRASIL, 2018).

A imputação de obrigações para a efetivação dos direitos do idoso, tanto no texto constitucional quanto no Estatuto (art. 3. ${ }^{\circ}$ ) obedeceram uma clara ordem progressiva e gradativa: em primeiro lugar a família, depois a sociedade, e só então o Estado, substanciando a doutrina da proteção integral, qual seja: todos são responsáveis solidariamente pelo cuidado e o resguardo dos direitos do idoso. Direitos estes elencados, dentre outros: a vida, a saúde, a alimentação, a educação, a cultura, o esporte, o lazer, o trabalho, a cidadania, a liberdade, a dignidade, o respeito e a convivência familiar e comunitária. Em última análise, podem receber a denominação de direitos fundamentais e sociais (art. 5. ${ }^{\circ}$ e 6. ${ }^{\circ} \mathrm{da} \mathrm{CF} / 88$ ), os quais, por disposição expressa (art. 5..$^{\circ}$ 1 ${ }^{\circ} \mathrm{CF} / 88$ ), tem aplicação imediata e direta, não apenas na esfera pública, mas também no âmbito das relações privadas, segundo o que a doutrina e jurisprudência nominou de eficácia horizontal dos direitos fundamentais. (RE, 2005) Importa dizer que os direitos fundamentais assegurados pela Constituição Federal vinculam os poderes públicos, mas também são direcionados à proteção em face e nas relações privadas.

Etimologicamente o termo família advém do latim ‘famulus', equivalendo ao conjunto de servos e dependentes de um chefe ou senhor, o que justifica ao longo dos tempos a construção de um conceito familiar estritamente patriarcal e de subordinação que, aos poucos, vai se transformando numa comunidade mais democrática e aberta. Em relação ao idoso, vê-se uma predileção pela manutenção e atendimento ao idoso no seio da família, definida pela Constituição (art. 226, $\S 4^{\circ}$ ) como a comunidade formada por qualquer dos pais e seus descendentes, não apenas advindo do casamento civil, nem tampouco da incialmente defendida exclusividade do homem e da mulher. Inobstante, sua compreensão dever ser feita a partir de uma feição ampla, considerando as dimensões biológicas, espirituais e sociais. Assim, esta entidade cultural, tendo em vista que em cada tipo de sociedade pode assumir uma configuração diferente, seja natural ou extensa, é a responsável primária pelo atendimento das necessidades e direitos do idoso. Importante observar que, em vista da mudança no perfil etário da população, os arranjos familiares atuais são bem diversos daqueles identificados em décadas passadas. Na atualidade, é bem mais comum a convivência interfamiliar e intergeracional, importando no estabelecimento de novas relações e novos conflitos.

Seguindo-se a ordem gradativa na atribuição de responsabilidades no atendimento do idoso, o arcabouço legislativo vigente impõe, em segundo lugar à sociedade, concebida conceitualmente pelo sábio (FERREIRA, 2013) como: reunião de pessoas unidas pela origem ou por leis; Estado social; grupo, bando (falando dos animais); união de pessoas ligadas por ideias ou por algum interesse comum; reunião de pessoas que se juntam para conversar ou conviver; reunião; conjunto de pessoas de uma mesma esfera; trato; convivência; casa onde se reúnem 
as pessoas unidas por um interesse ou ideias comuns; associação; solidariedade de interesses; parceria; sociedade anônima: empresa que tem o capital dividido em ações. Embora utilizando uma expressão indistinta, o legislador constituinte e ordinário quis envolver todo o grupamento humano que esteja próximo ao idoso na tarefa de bem zelar pela atenção a este grupo vulnerável.

Em terceiro lugar, na ordem legislativa de incumbência encontra-se o Estado, compreendido como esta entidade politicamente organizada numa determinada base territorial, com soberania, gerida por leis próprias. Inobstante, bem poderia ser identificado no poder público, posto que, em ordem hierárquica, vê-se o trânsito do privado para a esfera pública, equivalendo ao remanescente da obrigação protetiva ao idoso.

No franco desempenho de seu papel, o Estado conta com instrumentos de ação consubstanciadas nas políticas públicas, assim compreendidas como a atividade estatal de elaboração, planejamento, execução e financiamento de ações voltadas à consolidação do Estado Democrático de Direito e à promoção e proteção dos direitos humanos (AIHT, 2006). São os planos e mecanismos de ação que, sendo claramente identificadas, planejadas, implementadas e avaliadas, poderão corresponder ao pleno cumprimento da missão estatal de garantia de cabal equilíbrio nas relações sociais. Neste contexto, é a personalidade humana, em última instância, que inspira proteção e garantida, visando assegurar o seu pleno desenvolvimento.

\section{CONCEITOS RELEVANTES ACERCA DO DIREITO DA PERSONALIDADE, AFETO E VIOLÊNCIA}

A noção jurídica de personalidade é reconhecida em nossa sociedade como sendo:

[...] uma aptidão genericamente reconhecida: toda pessoa é dotada de personalidade. É a possibilidade de ser titular de relações jurídicas e de reclamar o exercício da cidadania, garantida constitucionalmente, que será implementada (dentre outras maneiras) através dos direitos da personalidade. (FARIAS, 2017, p. 180)

Neste panorama, os chamados direitos da personalidade caracterizam-se "por serem absolutos, indisponíveis relativamente, imprescritíveis e extrapatrimoniais” (FARIAS, 2017, p. 187) e vitalícios.

A imanência da personalidade compreendida como autoconhecimento, está em xeque na sociedade contemporânea moderna, globalizada, interconectada e influenciada por um turbilhão de demandas por consumo físico e psíquico, a ponto de provocar uma genuína crise 
de identidade. Clama-se por respeito à diversidade física, psicológica e de gênero, a qualquer custo e sob quaisquer condições. O ser humano passa por uma severa instabilidade, inspirada sobremaneira pelo liberalismo político e econômico, que vem provocando uma inflação de liberdades com escassas responsabilidades.

A Constituição Federal de 1988 consolidou o longo processo de redemocratização que o Brasil se submeteu, daí o compreensível o elenco de garantias aos direitos da personalidade. Logo em seguida, na revisão da legislação civil que concluiu com a edição da Lei 10.406/02 (Código Civil), pela primeira vez, o legislador cuidou da proteção dos direitos da personalidade, manifestando um compromisso de salvaguarda da pessoa humana como valor máximo. Vê-se, portanto, que os direitos da personalidade estão abonados tanto pela Constituição Federal quanto pelo Código Civil como intransmissíveis e irrenunciáveis, cujo exercício não pode sofrer limitação voluntária (art. 11). A eventual hipótese de lesão - ou a ameaça de lesão - assegura o direito de reclamar reparação por perdas e danos. Nesta categoria foram inseridos direitos relativos ao corpo, ao nome, a propriedade intelectual e a vida privada.

Fazendo uma compilação de várias definições de direitos da personalidade, Tartuce (2016, p. 146) assim escreve:

Mas, afinal, o que seriam então os direitos da personalidade? Segundo Rubens Limongi França, trata-se de "faculdades jurídicas cujo objeto são os diversos aspectos da própria pessoa do sujeito, bem assim as suas emanações e prolongamentos”. Para Maria Helena Diniz, os direitos da personalidade "são direitos subjetivos da pessoa de defender o que lhe é próprio, ou seja, a sua integridade física (vida, alimentos, próprio corpo, vivo ou morto); a sua integridade intelectual (liberdade de pensamento, autoria científica, artística e literária) e sua integridade moral (honra, recato, segredo pessoal, profissional e doméstico, imagem, identidade pessoal, familiar e social)”. Pablo Stolze Gagliano e Rodolfo Pamplona Filho, com a didática que lhes é peculiar, conceituam os direitos da personalidade como "aqueles que têm por objeto os atributos físicos, psíquicos e morais da pessoa em si e em suas projeções sociais”. Pelos conceitos transcritos, observa-se que os direitos da personalidade têm por objeto os modos de ser, físicos ou morais do indivíduo e o que se busca proteger com eles são, exatamente, os atributos específicos da personalidade, sendo personalidade a qualidade do ente considerado pessoa. Na sua especificação, a proteção envolve os aspectos psíquicos do indivíduo, além de sua integridade física, moral e intelectual, desde a sua concepção até a sua morte. Esse, na opinião deste autor, é o seu melhor conceito. 
Assim transpostos para o campo do idoso, as concepções de 'personalidade' e 'direitos da personalidade', vê-se que a doutrina da proteção integral, fulcrada na ideia de solidariedade enquanto objetivo fundante do Estado brasileiro (art. 3. ${ }^{\circ} \mathrm{CF}$ ), indica que há uma opção firme pelo núcleo familiar como o primeiro ambiente de cuidado e proteção. É nesta comunidade primária que se encontram (ou deveriam) o liame do afeto, sentimento que passa a ostentar um valor jurídico a partir do Código Civil, conforme alerta Dias (2007, p. 68-69), quando observa:

O afeto não é somente um laço que envolve os integrantes de uma família. Igualmente tem um viés externo, entre as famílias, pondo humanidade em cada família, compondo, no dizer de Sérgio Resende de Barros, a família humana universal, cujo lar é a aldeia global, cuja base é o globo terrestre, mas cuja origem sempre será, como sempre foi, a família [...]. O direito das famílias instalou uma nova ordem jurídica para a família, atribuindo valor jurídico ao afeto. [...] as relações de família, formais ou informais, indígenas ou exóticas, ontem como hoje, por mais complexas que se apresentem, nutrem-se, todas elas, de substâncias triviais e ilimitadamente disponíveis a quem delas queira tomar afeto, perdão, solidariedade, paciência, devotamento, transigência, enfim, tudo aquilo que, de um modo ou de outro, possa ser reconduzido à arte e à virtude do viver em comum. A teoria e a prática das instituições de família dependem, em última análise, de nossa competência de em dar e receber amor.

Um sentimento humano ganhou valor jurídico no ambiente familiar, passando a ostentar exigibilidade e orientar a intepretação dos deveres impostos ao grupo parental com reciprocidade, quando inseriu no texto constitucional (art. 229) que os pais têm o dever de assistir, criar e educar os filhos menores, e os filhos maiores têm o dever de ajudar e amparar os pais na velhice, carência ou enfermidade. Corolário do princípio da solidariedade familiar, o descumprimento deste dever do afeto pode ensejar o que a jurisprudência vem nominando de abandono afetivo, que pode gerar consequências econômicas, na medida e sob a concepção de que “amar é faculdade, cuidar é dever” (RE, 2012). Conforme observou com a maestria que lhe é peculiar, a Ministra Nancy Andrighi, no julgamento do REsp 1.159.242-SP, não se discute o amar - que é uma faculdade - mas sim a imposição biológica e constitucional de cuidar, que é dever jurídico.

Enquanto ser humano o idoso goza de todos os direitos fundamentais inerentes à pessoa, aqueles próprios da personalidade admitidos após importantes e intensas discussões doutrinárias e jurisprudenciais, elevadas ao patamar constitucional em 1988 e expressamente 
reconhecidos pelo Código Civil a partir do art. 11, como direitos essenciais ao desenvolvimento da pessoa humana, afim de resguardar a própria identidade (FARIAS, 2017).

Conforme já destacado, a orientação normativa é clara quanto a preferência pela manutenção do idoso no seio da família, concepção absolutamente legítima, na medida que, por via de regra, é rigorosamente do idoso que emerge o núcleo familiar reunido, em tese, pela relação de parentalidade. Paradoxalmente, a violação dos seus direitos mais caros ocorre justamente do convívio familiar.

Enquanto fundamento da República Federativa do Brasil, a dignidade da pessoa humana, é conceituada por Sarlet (2006, p.60) como:

[...] a qualidade intrínseca e distintiva reconhecida a cada ser humano o faz merecedor do mesmo respeito e consideração por parte do Estado e da comunidade, implicando, neste sentido, um complexo de direitos e deveres fundamentais que assegurem a pessoa tanto contra todo e qualquer ato de cunho degradante e desumano, como venham a lhe garantir as condições essenciais mínimas para uma vida saudável, além de propiciar e promover sua participação ativa e corresponsável nos destinos da própria existência e da vida em comunhão com os demais seres humanos.

O estatuto protetivo do idoso o colocou a salvo de qualquer tipo de negligência, discriminação, violência, crueldade ou opressão, bem como de todo atentado aos seus direitos, por ação ou omissão (Art. $4^{\circ}$ ). Inobstante, sabe-se que a violência pode se apresentar de diversas formas como psicológica, econômica, moral, sexual, familiar, social, institucional, por ação ou mesmo omissão daqueles que tem, por lei ou por contrato, o dever de cuidado, proteção e vigilância.

Segundo a Organização Mundial da Saúde, em relatório divulgado em 2002, a violência corresponde ao uso intencional da força física ou do poder, real ou ameaça, contra si próprio, contra outra pessoa ou contra um grupo ou uma comunidade que resulte ou tenha grande possibilidade de resultar em lesão, morte, dano psicológico, deficiência de desenvolvimento ou privação (MYNAYO, 2005, p. 15). Há também um conceito legal para a violência. Tratando de outro grupo igualmente vulnerável, a mulher no âmbito doméstico e familiar, a Lei 11.343/06 faz referência aos tipos de violência como sendo: física, psicológica, sexual, patrimonial e moral. Por violência física define qualquer conduta que ofenda a integridade ou a saúde corporal. Como violência psicológica conceitua qualquer conduta que 
cause dano emocional e diminuição da autoestima ou que prejudique e perturbe o pleno desenvolvimento ou que vise degradar ou controlar suas ações, comportamentos, crenças e decisões, mediante ameaça, constrangimento, humilhação, manipulação, isolamento, vigilância constante, perseguição contumaz, insulto, chantagem, ridicularização, exploração e limitação do direito de ir e vir ou qualquer outro meio que cause prejuízo à saúde psicológica e à autodeterminação. Como violência sexual, entende ser qualquer conduta que constranja a presenciar, a manter ou a participar de relação sexual não desejada, mediante intimidação, ameaça, coação ou uso da força; que induza a comercializar ou a utilizar, de qualquer modo, a sua sexualidade, mediante coação, chantagem, suborno ou manipulação; ou que limite ou anule o exercício dos direitos sexuais. A violência patrimonial, é entendida como qualquer conduta que configure retenção, subtração, destruição parcial ou total de seus objetos, instrumentos de trabalho, documentos pessoais, bens, valores e direitos ou recursos econômicos, incluindo os destinados a satisfazer suas necessidades. Por fim, a violência moral, é concebida como qualquer conduta que configure calúnia, difamação ou injúria.

Todos estes conceitos jurídicos são plenamente aplicáveis e podem validamente serem transportados para o cenário da violência contra o idoso. Corroborando esta simetria, a doutrina moderna vem ganhando foros jurisprudenciais, no sentido de se admitir a aplicação das medidas protetivas específicas previstas na Lei Maria da Penha (BRASIL, 2006) ao idoso vítima de violência no seio familiar. A doutrina assim reconhece:

Ora, se a Lei 11.343/2006 prevê medidas protetivas às mulheres para restabelecer o princípio da igualdade (já que são consideradas, pelo legislador, hipossuficientes para enfrentar os conflitos domésticos ou familiares), e a Constituição Federal proíbe qualquer forma de discriminação em face do sexo ou da idade, conclui-se que as medidas de proteção previstas na lei Maria da Penha são aplicáveis não apenas às mulheres, mas a qualquer pessoa que se encontre em posição de hipossuficiência em conflitos domésticos ou familiares. Os idosos, por exemplo, muitas vezes vivem em ambientes com intensos conflitos domésticos ou familiares, sem que tenham forças para enfrentar, por si, seus agressores (que na maioria das vezes são os próprios familiares). Em tais situações, é possível aplicar as medidas protetivas previstas na Lei Maria da Penha (Lei 11.343/2006) em favor desses idosos hipossuficientes (homens ou mulheres). (FREITAS JÚNIOR, 2006, p. 156-157). 
Aqui é imprescindível uma ressalva. O que se defende não é a aplicação direta, geral e irrestrita de todos os institutos da Lei Maria da Penha ao cenário de vulnerabilidade do idoso. Tanto a Lei n. ${ }^{\circ} 11.343 / 06$ quanto a Lei 10.741/03, facultam este intercâmbio dos institutos, quando determinam:

Art. 13. Ao processo, ao julgamento e à execução das causas cíveis e criminais decorrentes da prática de violência doméstica e familiar contra a mulher aplicar-se-ão as normas dos Códigos de Processo Penal e Processo Civil e da legislação específica relativa à criança, ao adolescente e ao idoso que não conflitarem com o estabelecido nesta Lei." e no Estatuto “Art. 45. Verificada qualquer das hipóteses previstas no art. 43, o Ministério Público ou o Poder Judiciário, a requerimento daquele, poderá determinar, dentre outras, as seguintes medidas. (grifo nosso).

Ambas propiciam o intercâmbio, permitindo concluir pela existência de um microssistema protetivo ao hipossuficiente, formado, dentre outras, pela Lei 11.343/06 (Lei Maria da Penha), Lei 10.741/03 (Estatuto do Idoso) e Lei 8.069/90 (Estatuto da Criança e do Adolescente), esta última que também ostenta institutos congêneres.

No pleno exercício da função judicante, aderi ao posicionamento ora proclamado, nos autos do processo n. ${ }^{\circ}$ 0000963-43.2015.8.16.0072:

A mera leitura do dispositivo em comento permite concluir que o Magistrado pode utilizar não só tais medidas do Estatuto do Idoso como também outras previstas nas demais leis que regem a proteção de vítimas e, ainda, pode fixar medidas inéditas no cenário legislativo com base no poder geral de cautela (art. 461, $\S 5^{\circ} \mathrm{CPC}$ ). Esse entendimento viabiliza a concretização dos direitos fundamentais da pessoa humana, as demais garantias entabuladas no artigo 230 da Constituição Federal, bem como a efetividade do próprio Estatuto do Idoso (Lei $\mathrm{n}^{\circ}$. 10.471/03). Ademais, por se tratar o requerente de pessoa idosa, determina o Estatuto do Idoso, em seu art. 82, caput, que "para defesa dos interesses e direitos protegidos por esta lei, são admissíveis todas as espécies de ação pertinentes" podendo o juiz, para o cumprimento de obrigação de fazer ou não-fazer, conceder tutela liminar ou após justificação prévia, impondo inclusive multa, independente de pedido do autor (art. 83 e §§), aplicando subsidiariamente o procedimento sumário previsto no CPC (art. 69)". 
Como sói acontecer em feitos desta natureza, após a implementação das medidas protetivas, não acudindo esta para a integral construção da pacificação e harmonia almejados na família assentes pelos idosos, já desgastados pelo peso da idade e o perecimento das forças físicas, agravada pelas doenças que normalmente acometem essa população, o feito foi extinto pela perda do objeto em vista do falecimento dos protegidos. Equivale a um indicativo de que decisões judiciais impostas vertical e unilateralmente pelo poder estatal, sobretudo no ambiente familiar, não são capazes de produzir a almejada pacificação social, se não forem criados perpetrados canais permanentes de diálogo e amadurecimento da própria entidade familiar, ainda que sob a mediação do Poder Judiciário.

É digno ainda de especial destaque, além da violência física, que em regra deixa vestígios pelo corpo, a violência moral, psicológica e financeira, que provoca rastros no inconsciente e nos sentimentos mais valiosos à população idosa que, em regra, muito estimam a honestidade, o bom nome, a honradez e a paz.

\section{UMA VISÃO DA VIOLAÇÃO DA DIGNIDADE DO IDOSO NA FAMÍLIA}

É sabido que por força da recomendação advinda do princípio da intervenção mínima ou última ratio, o uso do sistema de proteção aos bens jurídicos a que se propõe o direito penal, em vista de seu caráter fragmentário e subsidiário, somente está legitimado quando os demais ramos do direito se mostrarem ineficazes. Sob tal concepção, com a finalidade de coibir e reprimir tais práticas, o estatuto legal protetivo ao idoso enumerou condutas de intolerância, abandono, preconceito, negligência, maus-tratos e desvalorização como caracterizadoras de violência passíveis de punição.

Democraticamente distribuídos por todas as regiões do Brasil, multiplicam-se os casos de crimes cometidos contra o idoso em família, conforme podemos inferir pelo que se extrai dos julgados abaixo, sinteticamente expostos, apenas no essencial.

[...] suficientemente comprovada a prática do delito de maus-tratos pela acusada, que expôs a perigo a integridade física da vítima, idosa, com diversos problemas de saúde, cega e parcialmente surda, que permanecia sozinha na residência, tendo acesso apenas a alimentos vencidos, muitos já em estado de decomposição, negligenciando-lhe os cuidados necessários. - Comprovada a obrigação da ré para com a vítima, na medida em que a relação entre ambas iniciou-se apenas em decorrência da dependência da ofendida, desde o princípio conhecida 
pela autora do fato, que passou a perceber a integralidade de seus proventos mensais, comprometendo-se a lhe dispensar os cuidados necessários.” (TJRS, Recurso Crime No 71004014643, Turma Recursal Criminal, Relator: Eduardo Ernesto Lucas Almada, Julgado em 17/12/2012).

[...] os Apelantes, mediante tratamento desumano e degradante, expuseram a perigo a saúde psicológica da vítima, elementos do tipo previsto no artigo 99 do Estatuto do Idoso, não há que se falar em absolvição. [...]” (TJ-ES - APL: 00772384920128080011, Relator: Pedro Valls Feu Rosa, $1^{\text {a }}$ Câmara Criminal, Data de Publicação: 11/03/2016).

[...] impositiva a manutenção da condenação quando suficientemente comprovada a prática do delito de maus tratos pela acusada, que deixou a vítima, de oitenta e seis anos de idade, caída no chão, por mais de uma hora, sem ajudá-la a levantar-se. [...]” (Recurso Crime $\mathrm{N}^{\mathrm{o}}$ 71003194842, Turma Recursal Criminal, Turmas Recursais, (TJ-RS RC: 71003194842 RS, Relator: Luiz Antônio Alves Capra, Turma Recursal Criminal, Diário da Justiça do dia 30/08/2011).

[...] exercendo a função de cuidadora, submetia a vítima - uma senhora cadeirante, com dificuldade de locomoção, contanto 75 anos de idade , a intenso sofrimento físico e mental, representado por ações reiteradas de erguer a vítima da cadeira de rodas puxando-a pelos cabelos, aplicar tapas nas suas pernas com golpes de extrema violência, capazes a projetar os membros para o lado, despir a vítima segurando-a pelos cabelos, além de sacudir violentamente a cabeça da idosa puxando os cabelos. [...] as agressões covardes vistas nas imagens. [...] extrapolou os limites de simples maus tratos ao erguer a idosa da cadeira de rodas pelos cabelos, sacudir com raiva a cabeça da vítima agarrada aos seus cabelos e ainda agredi-la impiedosamente com violentos tapas nas pernas, tudo isso em ações reiteradas, durante o período em que exerceu a atividade de cuidadora - cerca de sete anos. O que demonstrou possuir nada mais foi do que uma vontade férrea de impor intensos sofrimentos físicos e morais à vítima, que além de idosa, necessitava de cuidados especiais por ser portadora de deficiência para se locomover. Como se verifica são fatos extremamente graves, demonstradores de perversão e covardia, onde grande dose de maldade restou explicitada para o fim de provocar intenso sofrimento físico e mental. [...] estamos diante de diversas condutas extremamente graves praticadas contra pessoa idosa e portadora de deficiência, por muito tempo agredida, cujo sofrimento suportando excedeu à normalidade do tipo penal violado.” [...] (TJ-RJ APL RJ 0005158-84.2014.8.19.0052, Relator: Des. Gilmar Augusto Teixeira, 8a Câmara Criminal, Data de Publicação: 25/09/2015).

[...] a privação de alimentos e cuidados indispensáveis ao idoso, constatada diante do quadro de anemia nutricional e das condições 
precárias de higiene e saúde, relatadas pela assistente social, resultando na morte da vítima pela falência múltipla de órgãos, dentre outras consequências, caracteriza o dolo na conduta do agente, configurando o crime de maus tratos previsto no Estatuto do Idoso.” (TJ-RO - EI: 00036479220158220000 RO 0003647-92.2015.822.0000, Relator: Desembargador Valdeci Castellar Citon, Câmaras Criminais Reunidas, Diário Oficial em 27/07/2015.)

[...] acusado que humilha e menospreza sua genitora, desferindo-lhe um chute na região das nádegas, durante um desentendimento. Relato da ofendida claro e seguro, não demonstrando sequer indícios de querer incriminar o acusado injustamente. Versão exculpatória do réu isolada nos autos.” (TJ-SP - Apelação: 122044220108260482, Relator: Des. Pinheiro Franco, Data de Julgamento: 01/03/2012, 5 a Câmara de Direito Criminal).

[...] indícios e circunstâncias que apontam que a causa da morte da ofendida foi a desnutrição. Omissão penalmente relevante. Agentes podiam e deviam agir para impedir o resultado. Dever de prestar alimentos, cuidado e proteção imposto por lei. Inteligência do art. 13, $\S 2^{\circ}$ A do Código Penal. Condição financeira e grau de instrução dos apelantes que não se prestam para lhes livrar da responsabilidade criminal.” (TJ-SC - Apelação Criminal: 2012.075394-0, Relator: Des. Volnei Celso Tomazini, Data de Julgamento: 21/05/2013, 2a Câmara Criminal).

Em todos estes casos absolutamente reais em que se rompeu as barreiras do silêncio e chegou à apreciação estatal, às escâncaras, evidenciam a profunda violação dos direitos da personalidade do idoso precisamente no seio da família, revelando o que as estatísticas oficiais apontam, em que pese as subnotificações. Não chega a ser incomum que os próprios idosos contemporizem, suportem a violência, convolando a inevitabilidade desse tipo de comportamento por parte de seus familiares jovens, a quem, evidentemente, quase nunca desejam ações repressivas por parte do Estado. Das subnotificações decorrem distorções estatísticas que criam obstáculos na identificação e combate desse tipo de conduta ilícita pela estrutura estatal.

Segundo dados divulgados em 2017 pela Secretaria de Direitos Humanos da Presidência da República, a ouvidoria do órgão recebeu mais de 133 mil denúncias de violações de direitos humanos em 2016, por intermédio do “disque 100”. No módulo Pessoa Idosa, 38\% das denúncias são relacionadas a violações por negligência, 26\% de violência psicológica, 20\% de abuso financeiro/econômico e violência patrimonial, e 13,8\% de violência física. A relação do suspeito com a vítima reflete também as tipificações das violações, que tem como categoria 

predominante a negligência. Pelo menos $54 \%$ das violações denunciadas foram praticadas por filho/a, 8\% por neto/a, 5\% por genro/nora e 3\% por marido/esposa. Este cenário doméstico é responsável por 70\% das violações (BRASIL, 2017).

Os registros oficiais dos órgãos de segurança pública também assentam na direção do crescimento do crime tendo como vítima o idoso no ambiente familiar. Estatísticas dão conta de que, em 62,1\% dos casos de violência contra o idoso ocorreram na residência da vítima (BRASIL, 2015).

\section{POSSIBILIDADES DE CONSTRUÇÃO ALTERNATIVA}

Revelando a violência contra o idoso na pauta social, o dia 15 de junho marca o Dia Mundial de Conscientização da Violência contra a Pessoa Idosa, data instituída em 2006, pela Organização das Nações Unidas (ONU) e pela Rede Internacional de Prevenção à Violência à Pessoa Idosa (INPES), com o objetivo de sensibilizar a sociedade para o combate das diversas formas de violência cometida contra a pessoa com idade igual ou superior a 60 anos.

Em vista da compreensível redução da higidez dos órgãos, funções e sentidos, os idosos estão dentre os segmentos populacionais que possuem fragilidades peculiares - o que também ocorre em relação às crianças, aos deficientes às gestantes, aos enfermos - para os quais as convenções sociais e mesmo o ordenamento jurídico positivado reserva prerrogativas não extensivas aos demais grupamentos. De outra parte, a humanidade vive com pressa, ávida por 'ganhar' tempo e realização instantânea. O estereótipo do idoso decadente e obsoleto, com passos e o raciocínio mais lentos, diverge deste ambiente social contemporâneo.

No enfrentamento destas situações assimétricas, é imperiosa a reconstrução do tecido social com estruturas familiares saudáveis. Várias ações e abordagens são necessárias, apoiada num forte e sincero compromisso político de integração, visando assegurar um amadurecimento com dignidade e segurança, desfrutando de plena realização de todos os direitos humanos liberdades fundamentais.

Em sua grande maioria, os idosos residem com as famílias. E é exatamente nesse espaço privilegiado de coexistência intergeracional que é preciso investir na qualificação de todos os seus integrantes para a construção de ambientes de respeito e dignidade. Embora evidente esta constatação, a aptidão humana para a fraternidade está cada vez menos presente nas famílias, tanto que, conforme reconhecido ao longo desta peça, é nesse círculo que ocorre, 
com preponderância, a violência física, psicológica, econômica e sexual por maus-tratos ou negligência com a senectude. Tal panorama notabiliza que este espaço deve ser o foco da atenção de todos os atores sociais na busca por mudança cultural na forma de conceber a pessoa idosa e o envelhecimento. O ambiente doméstico precisa ser preparado para atender às peculiaridades de estrutura física e psíquica do idoso. É necessário investir em formação de cuidadores e ações estatais de apoio às famílias que não ostentam condições de dispensar a atenção necessária por si mesmas.

Também a mídia ostenta um papel estratégico neste processo de transformação cultural, por intermédio da propagação de ideias positivas e o afastamento de estigmas e clichês ultrapassados, com campanhas oficiais ou de forma subliminar, inseridas nas grades ordinárias de programação, o que promove um efeito ainda mais eficiente. A promoção de fóruns estatuais e municipais com discussão sobre a condição do idoso pode interiorizar a temática e contribuir para a adoção de novas formas de se relacionar com o envelhecimento social.

Outra medida premente no sentido e efetivamente coibir e combater a violência cotidiana perpetrada contra o idoso no ambiente familiar é o cumprimento do disposto nos artigos 70 e 71 do Estatuto do Idoso, com a implantação dos órgãos de recebimento e apuração das denúncias - Delegacias de Polícia Especializadas, Defensoria Pública, Ministério Público e Conselhos de Direitos do Idoso.

\section{CONSIDERAÇÕES FINAIS}

É urgente e afligente um processo de educação social, internalizando valores ligados a solidariedade, inclusão social e tolerância, respeito à diversidade em suas variadíssimas formas. Sem esta reconstrução de valores e resgaste de princípios pragmáticos, todo o arcabouço legislativo protetivo ou punitivo isoladamente, não surtirá o efeito esperado ou será o suficiente para garantir o respeito aos direitos da personalidade do idoso.

É questão de sobrevivência social a transposição dos princípios de solidariedade e respeito à dignidade humana dos poéticos textos constitucionais, legais e dos tratados internacionais para a vida cotidiana. E esta missão não é exclusiva de nenhum, quando não, enseja o absoluto engajamento da família, da sociedade e do Estado.

\section{REFERÊNCIAS}


AITH, Fernando. Políticas públicas de Estado e de governo: instrumento de consolidação do Estado Democrático de Direito e de promoção e de proteção dos direitos humanos. In: BUCCI, Maria Paula Dallari. Políticas públicas - reflexões sobre o conceito jurídico. São Paulo: Saraiva, 2006.

BRASIL. Secretaria de Direitos Humanos. Dados sobre o envelhecimento no Brasil. Disponível em: $\quad<$ http://www.sdh.gov.br/assuntos/pessoa-idosa/dadosestatisticos/DadossobreoenvelhecimentonoBrasil.pdf>. Acesso em: 14 jan. 2018.

Lei $\mathrm{n}^{0}$ 8.842, de 4 de janeiro de 1994. Dispõe sobre a política nacional do idoso, cria o Conselho Nacional do Idoso e dá outras providências. Diário Oficial da União. Disponível em: <http://www.planalto.gov.br/ccivil_03/leis/l8842.htm>. Acesso em: 14 jan. 2018.

Lei $\mathrm{n}^{0}$ 11.340, de 7 de agosto de 2006. Cria mecanismos para coibir a violência doméstica e familiar contra a mulher, nos termos do § 80 do art. 226 da Constituição Federal, da Convenção sobre a Eliminação de Todas as Formas de Discriminação contra as Mulheres e da Convenção Interamericana para Prevenir, Punir e Erradicar a Violência contra a Mulher; dispõe sobre a criação dos Juizados de Violência Doméstica e Familiar contra a Mulher; altera o Código de Processo Penal, o Código Penal e a Lei de Execução Penal; e dá outras providências. Diário Oficial da União. Disponível em: <http://www.planalto.gov.br/ccivil_03/_ato2004-2006/2006/lei/l11340.htm>. Acesso em: 12 jan. 2017.

Ministério dos Direitos Humanos. Ouvidoria recebeu mais de 133 mil denúncias de violações de direitos humanos em 2016.2 Disponível em: $<$ http://www.sdh.gov.br/noticias/2017/abrc/disque-100-recebeu-mais-de-131-mil-denunciasde-violacoes-de-direitos-humanos-em-2016>. Acesso em: 12 jan. 2018.

Ministério dos Direitos Humanos. Plano de ação para o enfrentamento da violência contra pessoa idosa. Disponível em: <http://www.sdh.gov.br/assuntos/pessoaidosa/programas/plano-de-acao-para-o-enfrentamento-da-violencia-contra-pessoa-idosa $>$. Acesso em: 13 jan. 2018.

Secretaria Nacional de Segurança Pública. Diagnóstico dos homicídios no Brasil: subsídios para o pacto nacional pela redução de homicídios. 2015. Disponível em: $<$ http://www.justica.gov.br/sua-seguranca/seguranca-publica/analise-epesquisa/download/estudos_diversos/1diagnostico-homicidios.pdf $>$. Acesso em: 17 jan. 2018.

BUCCI, Maria Paula Dallari. Fundamentos para uma teoria jurídica das políticas públicas. São Paulo: Saraiva, 2013.

DIAS, Maria Berenice. Manual de direito das famílias. 4. ed. São Paulo: Editora Revista dos Tribunais, 2007.

FARIAS, Cristiano Chaves de. Direito civil - parte geral e LINDB. 15. ed. Salvador: Editora Juspodivm, 2017. 
FERREIRA, Aurélio Buarque de Holanda. Dicionário Aurélio da língua portuguesa. São Paulo: Positivo, 2013.

FREITAS JÚNIOR, Roberto. Leis penais especiais comentadas. Rio de Janeiro. Renovar, 2006.

LEAL, Luciana Nunes. População idosa vai triplicar entre 2010 e 2050, aponta publicação do IBGE. Estadão. 29 agosto 2016.2 Disponível em: <http://brasil.estadao.com.br/noticias/geral,populacao-idosa-vai-triplicar-entre-2010-e-2050aponta-publicacao-do-ibge,10000072724>. Acesso em: 14 jan. 2018.

MYNAYO, Maria Cecília. Violência contra idosos: o avesso do respeito à experiência e sabedoria. 2.ed. Brasília: Secretaria Especial de Direitos Humanos, 2005.

OLIVEIRA, Nielmar de. Expectativa de vida do brasileiro é de 75,8 anos, diz IBGE. EBC Agência Brasil. 01 dez. 2017. Disponível em: <http://agenciabrasil.ebc.com.br/pesquisa-einovacao/noticia/2017-12/expectativa-de-vida-do-brasileiro-e-de-758-anos-diz-ibge>. Acesso em: 14 jan. 2018.

SARLET, Ingo Wolfgang. Dignidade da pessoa humana e direitos fundamentais. 4. ed. Porto Alegre: Livraria do Advogado, 2006.

REsp 1.159.242-SP, Rel. Min. Nancy Andrighi, julgado em 24/4/2012. Disponível em: <http://www.migalhas.com.br/arquivo_artigo/art20120510-02.pdf> Acesso em: 14 jan. 2018.

TARTUCE, Flávio. Direito civil. Lei de introdução e parte geral. 12. ed., Rio de Janeiro. Forense Editora, 2016.

UN. United Nations. Outcomes on Ageing. Abril 2002. Disponível em: <http://www.un.org/en/development/devagenda/ageing.shtml>. Acesso em: 17 jan. 2018.

UNFPA. Fundo de População das Nações Unidas. Envelhecimento no Século XXI: celebração e desafio. Resumo Executivo (UNFPA), Nova York e pela HelpAge International, Londres. Disponível em: <https://www.unfpa.org/sites/default/files/pub-pdf/Portuguese-ExecSummary_0.pdf $>$. Acesso em: 17 jan. 2018. 